\title{
Genome engineering of stem cell organoids for disease modeling
}

\author{
Yingmin Sun ${ }^{1,2}$, Qiurong Ding ${ }^{1,2}$ \\ ${ }^{1}$ CAS Key Laboratory of Nutrition and Metabolism, Institute for Nutritional Sciences, Shanghai Institutes for Biological \\ Sciences, Chinese Academy of Sciences, Shanghai 200031, China \\ 2 University of Chinese Academy of Sciences, Shanghai 200031, China \\ $\triangle$ Correspondence: qrding@sibs.ac.cn (Q. Ding) \\ Received November 30, 2016 Accepted December 28, 2016
}

\begin{abstract}
Precision medicine emerges as a new approach that takes into account individual variability. Successful realization of precision medicine requires disease models that are able to incorporate personalized disease information and recapitulate disease development processes at the molecular, cellular and organ levels. With recent development in stem cell field, a variety of tissue organoids can be derived from patient specific pluripotent stem cells and adult stem cells. In combination with the state-of-the-art genome editing tools, organoids can be further engineered to mimic diseaserelevant genetic and epigenetic status of a patient. This has therefore enabled a rapid expansion of sophisticated in vitro disease models, offering a unique system for fundamental and biomedical research as well as the development of personalized medicine. Here we summarize some of the latest advances and future perspectives in engineering stem cell organoids for human disease modeling.
\end{abstract}

KEYWORDS pluripotent/adult stem cell, tissue organoid, genome editing, precision medicine

\section{INTRODUCTION}

The concept of precision medicine has been "hot" again in the public spotlight in recent years. The fundamental idea behind precision medicine is to integrate information from all aspects to create diagnostic and therapeutic strategies that are precisely tailored to each patient's requirement (Collins and Varmus, 2015). Recent advances in biotechnologies have led to an explosion of disease relevant molecular information, providing enormous opportunities to obtain the pathophysiological insights to develop personalized treatment. However, challenges exist that a model system is urgently needed for interpreting the information. An ideal system would have the following several features: 1) could recapitulate human body functions and disease development processes at different levels of molecular, cellular, tissue or organ; 2) could incorporate personalized disease information (e.g. genetic background, nutritional status, environmental disturbance, etc.); and 3) could be cultured in large scales for disease study and high-throughput drug screenings.

The discovery that mature cells can be reprogrammed to become pluripotent by Drs. John Gurdon and Shinya Yamanaka has opened the door that pluripotent stem cells from patients can be generated for disease modeling (Takahashi et al., 2007; Yu et al., 2007). Human pluripotent stem cells (hPSCs) as well as adult stem cells (ASCs) derived from tissues offer a unique in vitro cellular model system with several advantages. First, they have a human genome and thus are the most appropriate for studying human disease-relevant genetic variations. Second, under appropriate culture conditions, the cells can be directed to differentiate into a variety of terminal cell types. And the in vitro differentiation process often recapitulates aspects of normal development, providing the opportunity to study developmental and degenerative processes. Third, they can be maintained in culture for a large number of passages while keeping the genome integrity, thus are able to generate cellular materials in a large-scale for compound screenings.

In recent years, stem cells have been revealed to possess intrinsic abilities to generate complex structures in vitro through self-organization (Eiraku et al., 2008; Gaspard et al., 2008; Sato et al., 2009). When cultured in a 3D space and in the presence of suitable exogenous factors, stem cells form 
structures that mimic the architecture of a certain organ in vitro-these 3D complex structures are thus termed "organoids". Compared to 2D monocultures of a single cell type, organoids have the potential to recapitulate spatial organization of heterogeneous tissue-specific cells, cell-cell and cell-matrix interactions. Moreover, the emergence of genome editing technologies over the past a few years has made it feasible to efficiently engineer disease relevant genetic variations into stem cells (Hsu et al., 2014; Wang and Qi, 2016). Therefore, different organoids can be generated carrying patient specific disease-causing genetic and epigenetic background. Altogether, this is offering a unique model system for studying disease-relevant information and development of precision medicine. In this review, we discuss how human stem cells are self-organized to form different kinds of organoids, and how these tissue organoids, in combination with genome editing tools, can leverage our understanding of human disease development and will facilitate the realization of precision medicine. We will also highlight some of the existing limitations or challenges as well as future directions.

\section{ORGANOID FORMATION}

In general, organoids can be generated either from ASCs derived from tissues, or from PSCs, including patient-derived induced pluripotent stem cells (iPSCs). Stem cells are often placed within a hydrogel (e.g. Matrigel) in a 3D culture system, with supplement of suitable exogenous factors to mimic biochemical and physical cues of tissue development. Cells then exhibit some intrinsic ability to assemble into complex structures termed as organoids. These organoids are constituted of more than one cell type, often resemble architecture of a certain organ and exhibit some function specific to that organ, and this in vitro formation process is termed as "self-organization".

\section{Organoids derived from ASCs}

The development of the intestinal organoid culture system in 2009 was a major technological advance in this field (Sato et al., 2009). In this study, single Lgr $5^{+}$stem cells were isolated from mouse intestinal epithelium and cultured in a simple 3D culture system in which Matrigel was used as extra cellular matrix. A few key growth factors, such as WNT, Noggin, R-spondin and EGF, were supplemented mostly to maintain stem cell populations. Remarkably, these stem cells were found later to be able to form continuously expanding crypt-villus organoids that present near-physiological epithelium architecture reminiscent of normal gut. A similar culture system was subsequently adapted for generation of human intestinal organoids (Dekkers et al., 2013). Moreover, Lgr5 ${ }^{+}$stem cells derived from other organs were also found later to be able to self-organize to form different organoids, including stomach, colon and liver (Barker et al., 2010; Huch et al., 2013a, b; Sato et al., 2011; Stange et al., 2013). In summary, organoids that have been successfully generated with ASCs from primary murine or human tissues include intestine (mouse/human) (Dekkers et al., 2013; Sato et al., 2009; Yin et al., 2014), stomach (mouse/human) (Barker et al., 2010; Bartfeld et al., 2015; Schlaermann et al., 2016; Stange et al., 2013), oesophagus (mouse/human) (DeWard et al., 2014; Sato et al., 2011), colon (mouse/human) (Jung et al., 2011; Sato et al., 2011), liver (mouse) (Huch et al., 2013b; Huch et al., 2015), pancreas (mouse/human) (Boj et al., 2015; Huch et al., 2013a), lingual (mouse) (Hisha et al., 2013), lung (mouse) (Lee et al., 2014; Mondrinos et al., 2006; Mondrinos et al., 2014), taste bud (mouse) (Aihara et al., 2015; Ren et al., 2014), salivary gland (mouse) (Nanduri et al., 2014) and prostate (mouse/human) (Chua et al., 2014; Gao et al., 2014; Karthaus et al., 2014) (Table 1).

\section{Organoids derived from PSCs}

The use of PSCs to generate organoids circumvents the limitation of availability of human primary tissues where ASCs are derived from. Protocols are often established following the knowledge of developmental biology with manipulation of key growth factors or signaling pathways involved in germ layer and subsequent lineage specification. The first organoid generated from mouse and human PSCs are cortical tissues that displayed nicely the patterned structures mimicking the early aspect of cortical development (Eiraku et al., 2008; Gaspard et al., 2008). These studies have demonstrated the intrinsic ability of corticogenesis of stem cells when cultured in three-dimensional system with appropriate exogenous signals. From there, a variety of organoids of different tissues have been generated. The culture system in general is similar with the one used for organogenesis from ASCs, in which the proper 3D scaffold and biochemical factors are provided to induce the differentiation of PSCs down specific lineages, and differentiated cells will self-organize to form tissue-specific organoids. Current organoids that have been reported to be generated from mouse or human PSCs include stomach (mouse/human) (McCracken et al., 2014; Noguchi et al., 2015), intestine (mouse/human) (McCracken et al., 2011; Ootani et al., 2009; Spence et al., 2011; Watson et al., 2014; Workman et al., 2016), liver (human) (Ogawa et al., 2015; Sampaziotis et al., 2015; Takebe et al., 2013; Takebe et al., 2014), lung (human) (Dye et al., 2015), retina (mouse) (Eiraku et al., 2011), inner ear (mouse) (Koehler et al., 2013; Koehler and Hashino, 2014), brain (mouse/human) (Eiraku et al., 2008; Gaspard et al., 2008; Lancaster et al., 2013; Lancaster and Knoblich, 2014; Mariani et al., 2012; Muguruma et al., 2010, 2015; Qian et al., 2016), pituitary gland (mouse/human) (Ozone et al., 2016; Suga et al., 2011) and kidney (human) (Takasato et al., 2015) (Table 2).

\section{Construction of vascular and nervous systems}

While a wide variety of organoids have been generated, there are still huge gaps between in vitro generated 


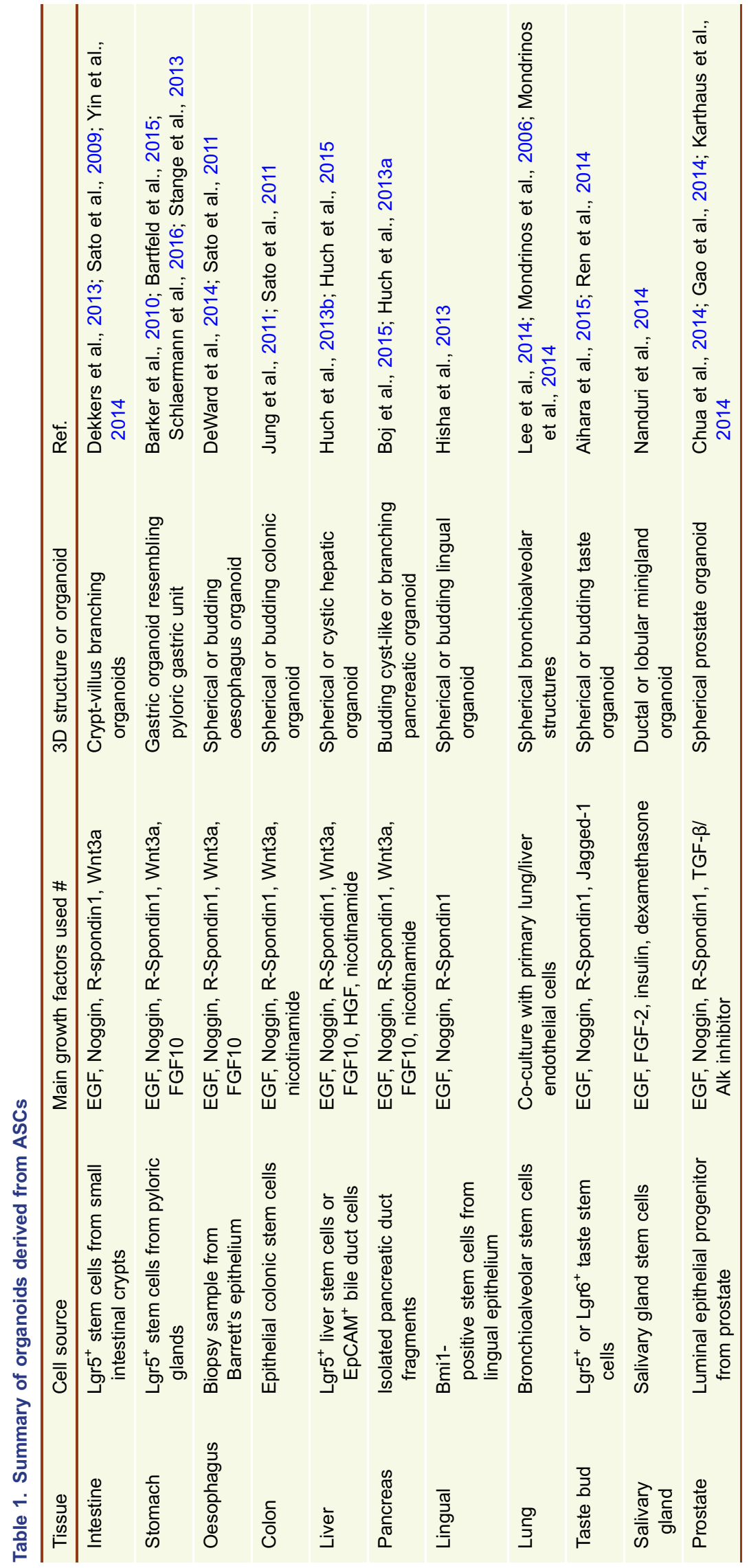




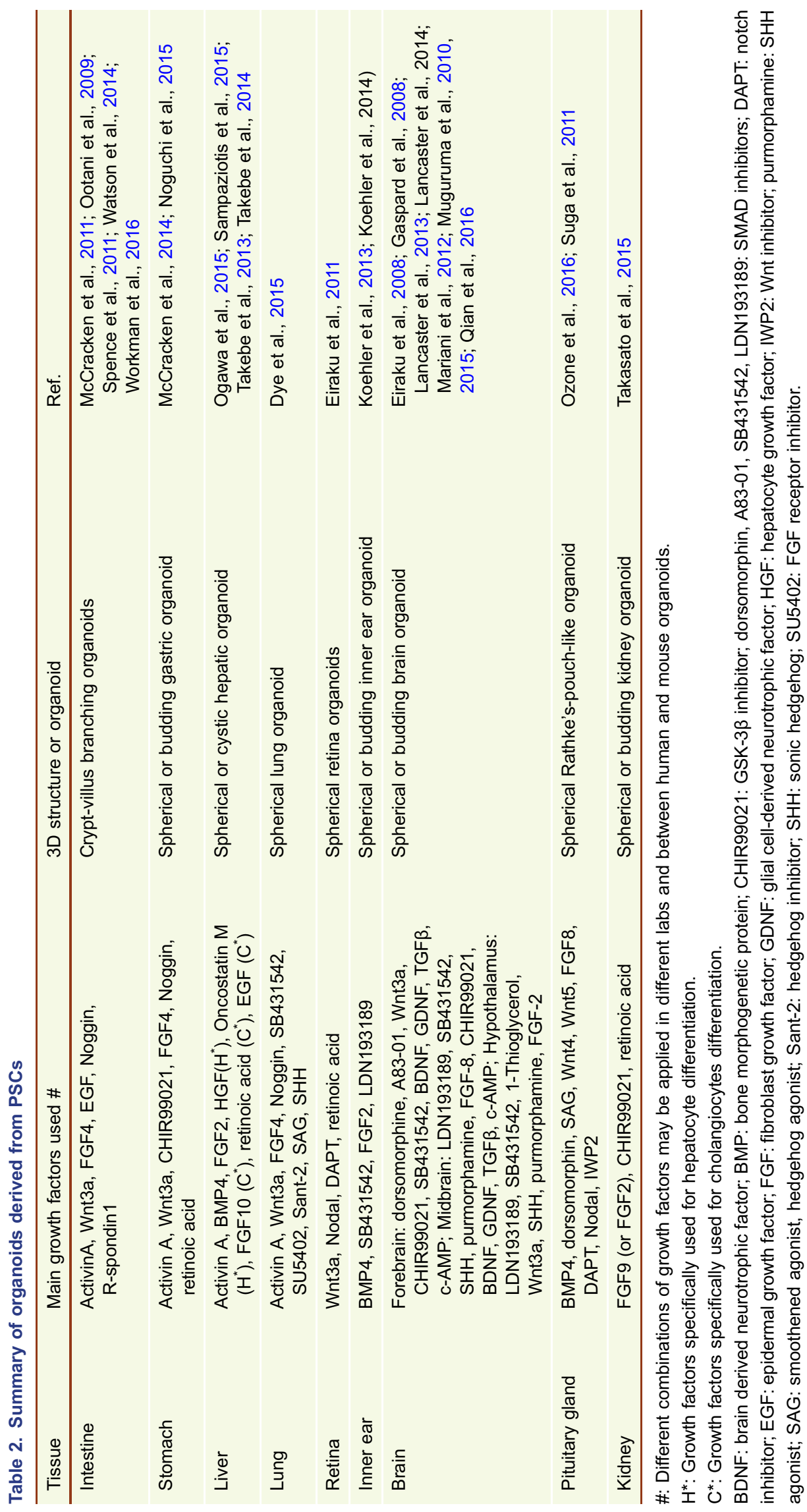


organoids and in vivo tissues. For example, organs in vivo often consist of hierarchically branched vascular networks. Almost all cells within an organ are surrounded by a few hundred microns of a capillary to permit sufficient nutrient and oxygen supply. Also organs in vivo have integrated peripheral nervous system that connects with the central nervous system. The nervous system in general serves as a communication relay, monitoring and coordinating internal organ function and responds to changes in the external environment. Thus, the construction of integrated vascular network and peripheral nervous system in organoids are important considerations in developing functional in vitro tissues.

There have been several approaches established for functional vascularization of generated organoids. One approach is to seed endothelial cells within the culture system that allows formation of blood vessels (Takebe et al., 2013; Takebe et al., 2014). An example comes from the generation of vascularized liver bud, in which hepatic endoderm cells derived from hPSCs were co-cultured with human umbilical vein endothelial cells (HUVECs) and human mesenchymal stem cells (MSCs) to form "liver bud". Upon transplantation into mice, these liver buds connected with the host vasculature and formed functional vascular networks similar in density and morphology to those of human adult livers. The other approach involves synthetic scaffolds, which are used to create micro-engineered $3 \mathrm{D}$ structures. Bio-printing methods can then be used for seeding the channels with multiple types of vascular cells (Visconti et al., 2010; Yin et al., 2016). For reconstruction of integrated nervous system in organoids, the first successful work was recently published that presented engineered hPSC-derived intestinal tissues with a functional enteric nervous system (Workman et al., 2016). The strategy taken was similar with seeding endothelial cells for vascularization. hPSC-derived neural crest cells (NCCs) and human intestinal organoids were mixed together through low-speed centrifugation in $3 \mathrm{D}$ growth conditions. Upon transplantation in vivo, these organoids formed neuroglial structures similar to a myenteric and submucosal plexus, and moreover, displayed functional interstitial cells of Cajal as well as electromechanical coupling that regulated waves of propagating contraction.

Other than lack of complete vascular and nervous systems, there are still key components lacking in current organoids. For instance, stromal components including immune cells that have important disease implications are missing, which has largely limited the applications in modeling inflammatory responses (e.g. to infection or drugs). Additional challenges exist that the underlying mechanisms that how stem cells self-organize remains obscure. It is therefore often difficult to control the cell type, cell organization, cell-cell and cell-matrix interactions. Recent advances in biomaterials, micro/nanotechnology and bioengineering approaches offer some promising solutions (Yin et al., 2016). Biomimetic systems can be engineered to incorporate extrinsic biochemical and biophysical signals to modulate the stem cell niche, to control cell-cell and cell-matrix interaction, oxygen distribution, local $\mathrm{pH}$ levels and nutrient transport within organoids (Yin et al., 2016).

\section{GENOME ENGINEERING}

While organoids can be generated from stem cells isolated directly from patient's tissues or from patient iPSCs for disease modeling, appropriate control is required to establish disease-relevant phenotypes for mechanism study and compound screenings. Availability of strict control groups is becoming even more important in organoid systems, in which huge systematic variations exist due to complicated processes including derivation and differentiation of stem cells as well as diverse engineering tools used for organoid formation. The most rigorous possible control would be a cell line that differ only with respect to disease mutations compared to the original cell line, i.e., otherwise isogenic cell lines. Such a strategy would require the ability to efficiently introduce specific genetic alterations into the genomes of hPSCs at will.

Fortunately, the discovery of different targeted nucleases in recent years, especially the clustered regularly interspaced short palindromic repeats (CRISPR)/CRISPR-associated (Cas) system, has enabled researchers to accurately manipulate genomic sequences in different cells and model organisms. Within a couple of years, genome-editing technology has been rapidly developed for a variety of research and translational applications, making it an extremely powerful tool that can facilitate disease modeling by recapitulating the genetic defects.

Although with different working modules, most of the genome-editing tools share the same editing methodology by introducing double stranded-breaks (DSBs) into a desired genomic site. Cells react to DSBs by initiating DNA repair processes, either through non-homology end joining (NHEJ) or homology directed recombination (HDR). DNA repaired by NHEJ is error-prone, which can introduce small insertions or deletions (indels) into a genomic locus-causing frameshift thus knocking out the gene in coding region, or destroying a DNA regulation element in non-coding region; whereas DNA repaired by HDR can be used to introduce precise single nucleotide alterations or insert a whole gene into a specific genomic locus by providing an exogenous DNA template. When multiple DSBs have been made simultaneously into the cells (so called "multiplex"), chromatin structure changes, such as truncation, or even translocation or duplication, can also be made, albeit at a relatively lower rate (Hsu et al., 2014; Wang and Qi, 2016).

With genome editing tools, stem cell lines from patients can be efficiently "cured" to correct the disease relevant genetic variants to establish isogenic control groups (Fig. 1A). In the case when patients carrying certain genetic mutations are not accessible, wild-type stem cells can also be introduced with genetic variants to create "patient" cell 
A Wild-type
hPSCs

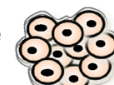

enome editing
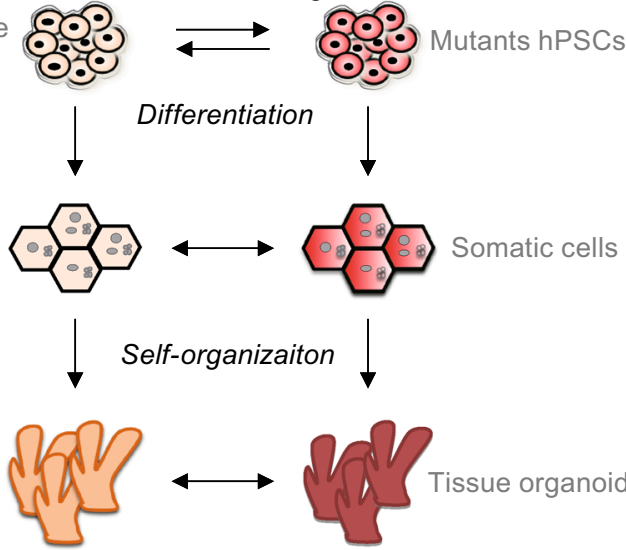

C

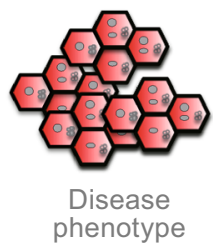

High-throughput genome editing

Figure 1. Applications of genome engineering in disease modeling. With genome editing tools, stem cell lines from patients can be efficiently "cured" to correct the disease relevant genetic variants; or wild-type stem cells can also be introduced with genetic variants to create "patient" cell lines for disease modeling (A). Catalytically dead nucleases, such as deactivated Cas9 (dCas9), can be fused to different functional effectors and carry out molecular functions other than genome editing (B). High-throughput genetic screenings can be developed using genome editing tools to illuminate genes or signaling pathways involved in disease development (C).

lines (Fig. 1A). Indeed, with this strategy a variety of genetic variants, either in the same gene or in multiple genes, can be introduced into a single cell line so that they are on the same genetic and epigenetic background (Ding et al., 2013). This allows for direct comparison of the effects of the different genetic variants, setting up a panel of disease models for study of mutation-specific disease phenotypes and for screening of tailored disease treatments (Musunuru, 2013).

Not only genome editing tools can be used for engineering DNA sequences, taking advantage of their ability to target a specific genomic region, catalytically dead nucleases, such as deactivated Cas9 (dCas9), can be fused to functional effectors and carry out functions other than genome editing (Wang and Qi, 2016) (Fig. 1B). For example, dCas9 has being fused with transcriptional activators or repressors to regulate gene expression at the transcriptional levels (Cheng et al., 2013; Gilbert et al., 2013; Perez-Pinera et al., 2013a; Pinera et al., 2013b; Qi et al., 2013); with epigenetic regulators (e.g. acetyltransferase and histone demethylase) to manipulate the epi-status of a genomic region (Amabile et al., 2016; Hilton et al., 2015; Kearns et al., 2015; Thakore et al., 2015); with fluorescent proteins (e.g. green fluorescent protein, GFP) for imaging of specific DNA sequences (Chen et al., 2013; Ma et al., 2016a, b; Nelles et al., 2016; Schmidt et al., 2016); and more recently with
B
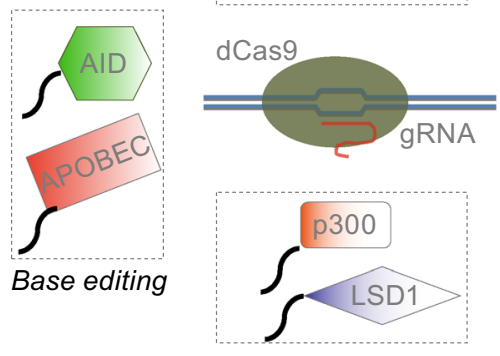

Epigenetic regulation

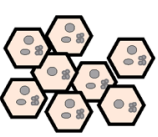

Wild-type phenotype

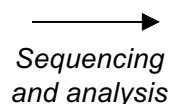

Sequencing
and analysis

Potential target

genes
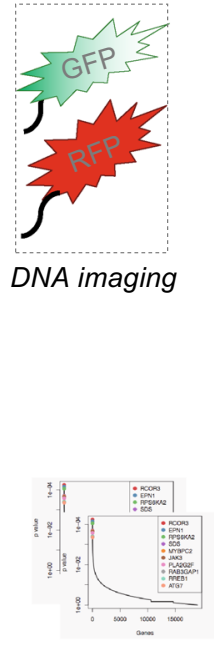

cytidine deaminase enzymes to introduce the $\mathrm{C}->\mathrm{T}$ (or G->A) transitions, offering a more efficient approach for base editing than HDR (Komor et al., 2016; Ma et al., 2016a, b; Nishida et al., 2016).

Besides making specific genetic or epigenetic alterations to cells or model organisms, genome-editing tools, especially CRISPR/Cas9, have also been developed for highthroughput genetic screenings (Fig. 1C). A variety of gRNA libraries are currently available through Addgene (www. addgene.org) that allows to screen tens of thousands of genes genome-wide or a specialized group of genes (e.g. kinases, transcription factors) for gene targets that are responsible for a biological phenotype of interest. For instance, screens have been performed to dissect genes or signaling pathways involved in the development of tumor drug resistance (Koike-Yusa et al., 2014; Konermann et al., 2015; Gilbert et al., 2014; Shalem et al., 2014; Wang et al., 2014; Zhou et al., 2014), transformation and metastasis of cancer cells (Chen et al., 2015), pyroptotic cell death (Parnas et al., 2015; Shi et al., 2015) or mitochondrial deficiency (Jain et al., 2016). Guide RNA libraries can also be customized to target a specific non-coding genomic region in order to dissect potential DNA regulating elements for a certain cellular phenotype in a high-throughput manner (Canver et al., 2015; Sanjana et al., 2016). Moreover, a 
paired-guided RNA CRISPR/Cas9 library has recently been generated to screen for lincRNAs by performing multiplex targeting to delete the entire lincRNA sequences (Zhu et al., 2016). All these applications can greatly facilitate the manipulation of genetic and epigenetic status in organoids for disease modeling as well as obtaining the pathophysiological insights for disease development and treatment.

\section{DISEASE MODELING}

Disease modeling with stem cells, especially with patient derived iPSCs, has been applied to a variety of human diseases (Musunuru, 2013). Although current stem cells-generated disease models mostly rely on $2 \mathrm{D}$ monocultures of a single cell type, these cellular models have been proven to be valuable in modeling human diseases with high physiological relevance, and meantime offering abundant cellular materials for high-throughput compound and genetic screenings. One of the best examples came from studies of human premature aging. One study focused on HutchinsonGilford progeria syndrome (HGPS) disease, which is caused by mutation in the LMNA gene. In this study, patient iPSC and isogenic control iPSC lines were generated and differentiated into vascular smooth muscle cells and fibroblasts for disease modeling (Liu et al., 2011). Furthermore, by setting up a high-throughput siRNA screen with these cells, suppressed NRF2 antioxidant activity has been successfully identified as a driver mechanism in HGPS (Kubben et al., 2016). Instead, a different study also focused on human premature aging used a stem cell model generated by knocking out exons of the WRN gene in wild-type embryonic stem cell lines and subsequently differentiated to MSCs to mimic the Werner syndrome (WS) (Zhang et al., 2015). Studies with this cell model revealed a significant role for $W R N$ in maintaining heterochromatin stability. A chemical screen was later performed on these WRN-deficient MSCs, and interestingly, Vitamin $\mathrm{C}$ was found to be able to rescue many of the aging features, suggesting it be a potential treatment to alleviate Werner syndrome (Li et al., 2016).

With the recent development of organoid culture systems, three-dimensional organoids offer new opportunities for biomedical research in that diseases can be modeled at the organ or tissue level. One of the most developed model system with $3 D$ organoids is from the intestine, representing beautiful multiple approaches by which organoid disease models can be generated and used to study diseases (Fig. 2).

\section{Infectious diseases}

As mucin-rich barriers are established inside 3D organoids from intestine, intestinal organoids that derived either from crypt or PSCs offered a unique cellular system to study pathophysiology of bacterial-epithelia interactions (Forbester et al., 2015; Leslie et al., 2015; Wang et al., 2015; Wilson et al., 2015; Zhang et al., 2014). Upon the invasiveness of bacterial (e.g. strains of Salmonella and Clostridium), morphologic changes and disruption of epithelial tight junctions were observed in infected organoids, presenting one nice experimental system to study host-bacterial interactions. Similar studies have also been performed to study Helicobacter pylori infection using gastric organoids, demonstrating the potential for wider studies of the human microbiome using 3D organoid models of epithelial tissues (Bartfeld et al., 2015; Wroblewski et al., 2015).

\section{Hereditary diseases}

There have been several studies in which intestinal organoids carrying specific disease-relevant mutations were generated for pathophysiological study and for screening of new pharmaceutical interventions. For example, a simple and robust assay that allows the diagnosis, functional study and identification of personalized medicine was developed using intestinal organoids derived from people who suffer from cystic fibrosis (Dekkers et al., 2013). In another study focusing on multiple intestinal atresia (MIA) - a rare cause of bowel obstruction, mutations in tetratricopeptide repeat domain-7A (TTC7A) were identified from patients using linkage analysis and whole-exome sequencing (Bigorgne et al., 2014). Further studies using intestinal organoids derived from MIA patients revealed an inversion of apicobasal polarity of the epithelial cells due to aberrantly increased Rho kinase activity, suggesting a potential treatment with pharmacological inhibition of Rho kinase. Another recent study focused on Hirschsprung's disease with an impaired neural crest development being the underlying cause (Workman et al., 2016). Study was carried out using the most advanced intestinal organoids that have incorporated a functional enteric nervous system. With these organoids, the molecular basis of pathophysiology of Hirschsprung's disease caused by a mutation in the $P H O X 2 B$ gene was carefully investigated.

\section{Cancer}

Organoids can also be adapted to develop in vitro models of several types of malignancies from intestine/colon, stomach, pancreas, prostate, brain and lung (Schweiger and Jensen, 2016). Cancer organoids can be directly generated from patients' primary cells, offering a model system that can incorporate patient specific disease information. With such a system, screens can be performed for treatments with high efficacy and minimal side effect (van de Wetering et al., 2015). Organoids can also be used to study the role and requirement of known driven mutations in cancer development (Schweiger and Jensen, 2016). For instance, in one study the most common mutations in colorectal cancer were introduced to wild-type human intestinal organoids with 
A
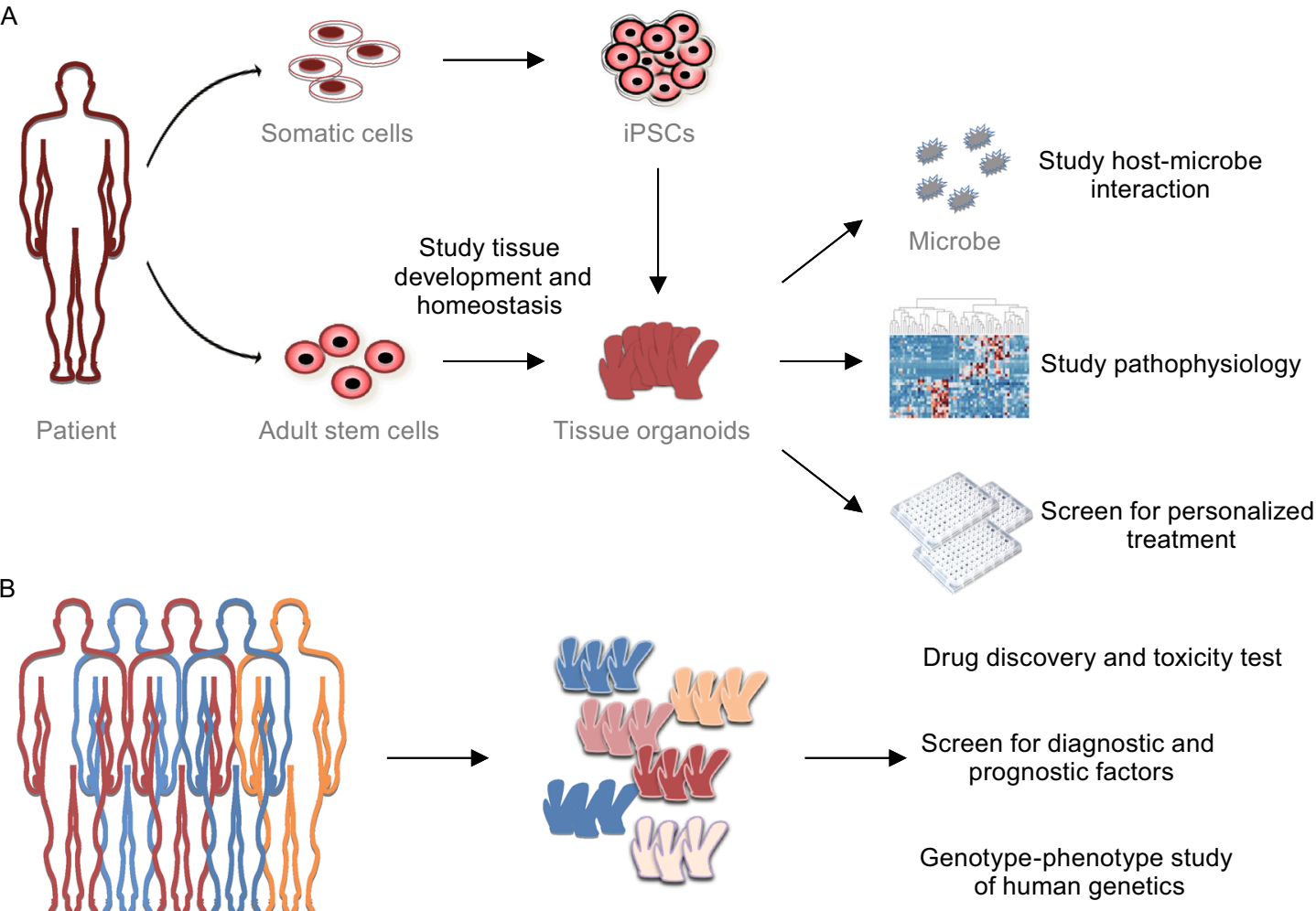

Drug discovery and toxicity test

Population

Organoid biobank

C

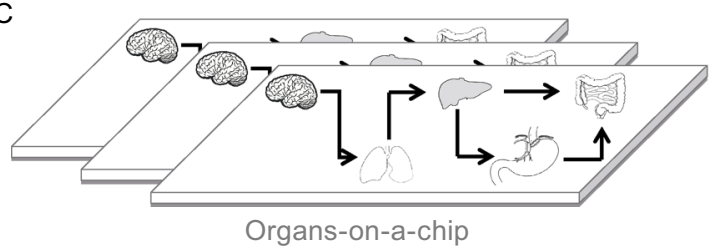

Drug discovery and toxicity test

Study complex physiology

e.g. human nutriology

Figure 2. Applications of organoid technology in basic and translational research. Tissue organoids can be derived from patient iPSCs or ASCs. The in vitro development of organoids offers a cellular system for studying the contribution of various signaling pathways in human tissue development and homeostasis. Established organoids can be used as a model system to study infectious diseases or tissue specific responses to toxins. Organoids with patient-specific disease information can also be generated for pathophysiology study, and can be expanded in a large scale for discovery of personalized treatment through high-throughput screenings (A). Biobanks with organoids generated from human populations are being established, which will provide high valuable resources that can be used to carry out preclinical efficacy and toxicity test of candidate drugs, screen for diagnostic and prognostic factors, and delineate genotype-phenotype causality in conjunction with current genetic studies (e.g. GWAS) (B). Complemented with advances in bioengineering approaches, "organs-on-a-chip" can be built up containing multiple tissues that can offer an efficient system for drug discovery and study of more complex physiological processes, such as human nutriology (C).

different combinations (Drost et al., 2015). Results revealed that organoids carrying mutants in all 4 genes (APC, TP53, $K R A S$ and $S M A D 4$ ) can grow self-sufficiently and form solid tumors with features of invasive carcinoma upon subcutaneous engrafting, whereas combined loss of $A P C$ and $P 53$ was sufficient to induce extensive aneuploidy. A similar study compared the metastasis ability of intestinal organoids carrying mutations in all 5 genes (APC, TP53, KRAS, SMAD4 and PI3KCA) with another engineered organoids derived from patient-derived chromosome-instable adenomas (Matano et al., 2015). Results indicated that although these five mutations are sufficient for tumor development, additional molecular lesions are required for invasive behavior. Similar approach can be extremely useful for 
dissecting the causality of a specific mutation and/or combinations of mutations identified in individual patients as well as in large cancer genomic studies.

\section{Neurological diseases}

Besides disease models generated with intestine organoids, organoids derived from other tissues have also being used for modeling diseases, such as liver, stomach and pancreas etc. (Drost et al., 2015). In particular, brain organoids can be generated that can be used to model various neurodevelopmental or neurodegenerative disorders that have been difficult or impossible to model in animals. For example, brain organoids derived from patient iPSCs have been used to study the developmental pathogenesis of microcephaly caused by a mutation in CDK5RAP2 (Lancaster et al., 2013). With further development, it will not be surprising that cerebral organoids can also be applied to model and study disorders such as autism (Mariani et al., 2015), virus exposure (Qian et al., 2016) and even adult-onset disorders like neurodegenerative diseases in the future. It is worth mentioning that unlike cultured primary neurons, PSCs can be maintained for a large number of passages, thus these diseased brain organoids can be expanded for high-throughput screenings for compounds for disease treatment, offering a model system with huge potential in drug discovery to brain diseases.

It is clear that the generation of various $3 D$ organoids provides unprecedently a sophisticated model system that has the potential to model a wide variety of human diseases; still limitations exist at least with current systems. Compared with monolayer model systems, which can be readily standardized, 3D organoids generation combines differentiation of stem cells, aggregation of multi-types of cells and diverse bioengineering approaches, making it extremely difficult for standardization and hard for groups to compare results between systems. Another challenge comes from the maturation of organoids in vitro. Although 3D organoids displayed in general more matured cellular phenotypes compared to monolayer-cultured cells, most of organoids cannot approach fully maturation until transplanted in vivo. Furthermore, microenvironment and hormone levels, the local $\mathrm{pH}$ levels, the nutrition status as well as the microbiome of the human body cannot be fully reproduced in an in vitro organoid. Thus it is critically important to have thorough characterization of the in vitro organoid system with regard to the extent of recapitulation of in vivo development before it is used for biomedical research and therapeutics. Besides, incorporation of functional vascular and nervous systems, as well as stromal components for inflammatory studies in organoids still await more development.

\section{OUTLOOK}

The common failures to translate promising preclinical drug candidates into clinical success and the endeavors to realize precision medicine highlight the urgent call for a model system with easy accessibility, high physiological relevance and ability to incorporate patient-specific disease background. Organoids derived from stem cells have proven to be such a system that has the potential to recapitulate crucial aspects of development, homeostasis and disease of human body and to inherit patient-specific disease information as well as has the capacity to expand indefinitely.

With these advantages, organoids technology provides a unique model system for a wide range of applications in both basic research and translational studies. The in vitro development of organoids itself offers a cellular system for studying the contribution of various signaling pathways in human tissue development and homeostasis. Established organoids can also be used to study host-microbe interaction and even responds to environmental and food processinggenerated toxins. When incorporated with disease related information by biochemical and genetic manipulations, human disease models can be established and used for identification of driver mutations and key pathophysiology pathways in disease conditions. Furthermore, organoids carrying specific disease information of a patient can be grown in large scale for preclinical drug screenings for treatment with high efficacy and minimal side-effect that being tailored to the patient's requirement (Fig. 2A). Importantly, biobanks are being established collecting human organoids that can potentially offer organoids of human populations, which can be used for preclinical efficacy and toxicity tests of candidate drugs, screen for diagnostic and prognostic factors, and study of genotype-phenotype causality in conjunction with various genetic studies (e.g. genome-wide association studies) (Fig. 2B). Moreover, it is also clear that organoid technologies offer a potential large source of donor tissues for transplantation use.

Complemented with advances in bioengineering approaches, it is possible to build up organoids from different tissues together or even a functional gastrointestinal system using microfludic devices termed "organs-on-a-chip" (Fig. 2C). Although still early in their development, several organ-on-a-chip assay formats have already been evaluated. For example, a four-organ-chip system was established that included human liver, skin, intestine and kidney (Maschmeyer et al., 2015). It is foreseen that generation of such complex, stem-cell-based, multi-organ in vitro system would allow us to model much more complicated physiological processes, such as human nutriology (Ben-Zvi and Melton, 2015).

Genome editing technology emerges as an extremely powerful tool that can greatly advance organoid-based research and therapies. With various genome editing tools, genetic variants, epigenetic alterations, or even changes in chromatin structure can be efficiently corrected from patient cells or introduced into wild-type cells. A variety of human disease models can therefore be established for pathophysiology study and treatment development. Besides, different high-throughput genome editing platforms are offering remarkable resources that can be adapted to screen for 
potential therapeutic targets in combination with disease models. It is also possible that organoids can be edited to possess extra functions that facilitate the in vitro organoid formation and maturation. For instance, certain support cells can be edited to enhance niche function or to cooperate better with biomimetic scaffolds. Perhaps the most exciting application lies in organoid-based therapeutics in the future. Organoids derived from patients with hereditary diseases can be "cured" with genome editing to correct the diseasecausing mutation(s), and functional organoids can then be transplanted back into patients to improve tissue functionality. Altogether, although challenges exist that the current organoids system still need substantial development, this system have already found utility in many basic biological and therapeutic fields to advance new knowledge and to advance us closer to therapeutics for diseases that previously appeared untouchable.

\section{ACKNOWLEDGMENTS}

This work was supported by the National Natural Science Foundation of China (Grant Nos. 81600650 to Y.S., and 31670829 to Q.D.), China Postdoctoral Science Foundation (2016M601666 to Y.S.), the Hundred Talents Program of the Chinese Academy of Sciences (Q. D.), the National Youth 1000 Talents Program (Q.D.), and the Shanghai Pujiang Program (15PJ1409200 to Q.D.).

\section{ABBREVIATIONS}

ASCs, adult stem cells; DSBs, double stranded-breaks; HDR, homology directed recombination; HGPS, Hutchinson-Gilford progeria syndrome; hPSCs, human pluripotent stem cells; HUVECs, human umbilical vein endothelial cells; iPSCs, induced pluripotent stem cells; MSCs, mesenchymal stem cells; NCCs, neural crest cells; NHEJ, non-homology end joining; WS, Werner syndrome.

\section{COMPLIANCE WITH ETHICS GUIDELINES}

Yingmin Sun and Qiurong Ding declare that they have no conflict of interest.

This article does not contain any studies with human or animal subjects performed by the any of the authors.

\section{OPEN ACCESS}

This article is distributed under the terms of the Creative Commons Attribution 4.0 International License (http://creativecommons.org/ licenses/by/4.0/), which permits unrestricted use, distribution, and reproduction in any medium, provided you give appropriate credit to the original author(s) and the source, provide a link to the Creative Commons license, and indicate if changes were made.

\section{REFERENCES}

Aihara E, Mahe MM, Schumacher MA, Matthis AL, Feng R, Ren W, Noah TK, Matsu-ura T, Moore SR, Hong Cl et al (2015)
Characterization of stem/progenitor cell cycle using murine circumvallate papilla taste bud organoid. Sci Rep 5: 17185

Amabile A, Migliara A, Capasso P, Biffi M, Cittaro D, Naldini L, Lombardo A (2016) Inheritable silencing of endogenous genes by hit-and-run targeted epigenetic editing. Cell 167:219-232

Barker N, Huch M, Kujala P, van de Wetering M, Snippert HJ, van Es $\mathrm{JH}$, Sato T, Stange DE, Begthel $\mathrm{H}$, van den Born $\mathrm{M}$ et al (2010) Lgr5(+ve) stem cells drive self-renewal in the stomach and build long-lived gastric units in vitro. Cell Stem Cell 6:25-36

Bartfeld S, Bayram T, van de Wetering M, Huch M, Begthel $H$, Kujala P, Vries R, Peters PJ, Clevers H (2015) In vitro expansion of human gastric epithelial stem cells and their responses to bacterial infection. Gastroenterology 148:126-136

Ben-Zvi D, Melton DA (2015) Modeling human nutrition using human embryonic stem cells. Cell 161:12-17

Bigorgne AE, Farin HF, Lemoine R, Mahlaoui N, Lambert N, Gil M, Schulz A, Philippet P, Schlesser P, Abrahamsen TG et al (2014) TTC7A mutations disrupt intestinal epithelial apicobasal polarity. J Clin Invest 124:328-337

Boj SF, Hwang Cl, Baker LA, Chio II, Engle DD, Corbo V, Jager M, Ponz-Sarvise M, Tiriac H, Spector MS et al (2015) Organoid models of human and mouse ductal pancreatic cancer. Cell 160:324-338

Canver MC, Smith EC, Sher F, Pinello L, Sanjana NE, Shalem O, Chen DD, Schupp PG, Vinjamur DS, Garcia SP et al (2015) BCL11A enhancer dissection by Cas9-mediated in situ saturating mutagenesis. Nature 527:192-197

Chen B, Gilbert LA, Cimini BA, Schnitzbauer J, Zhang W, Li GW, Park J, Blackburn EH, Weissman JS, Qi LS et al (2013) Dynamic imaging of genomic loci in living human cells by an optimized CRISPR/Cas system. Cell 155:1479-1491

Chen S, Sanjana NE, Zheng K, Shalem O, Lee K, Shi X, Scott DA, Song J, Pan JQ, Weissleder R et al (2015) Genome-wide CRISPR screen in a mouse model of tumor growth and metastasis. Cell 160:1246-1260

Cheng AW, Wang H, Yang H, Shi L, Katz Y, Theunissen TW, Rangarajan S, Shivalila CS, Dadon DB, Jaenisch R (2013) Multiplexed activation of endogenous genes by CRISPR-on, an RNA-guided transcriptional activator system. Cell Res 23:11631171

Chua CW, Shibata M, Lei M, Toivanen R, Barlow LJ, Bergren SK, Badani KK, McKiernan JM, Benson MC, Hibshoosh H et al (2014) Single luminal epithelial progenitors can generate prostate organoids in culture. Nat Cell Biol 16:951-961

Collins FS, Varmus H (2015) A new initiative on precision medicine. N Engl J Med 372:793-795

Dekkers JF, Wiegerinck CL, de Jonge HR, Bronsveld I, Janssens $\mathrm{HM}$, de Winter-de Groot KM, Brandsma AM, de Jong NW, Bijvelds MJ, Scholte BJ et al (2013) A functional CFTR assay using primary cystic fiborsis intestinal organoids. Nat Med 19:939-945

DeWard AD, Cramer J, Lagasse E (2014) Celluar heterogeneity in the mouse esophagus implicates the presence of a nonquiescent epithelial stem cell population. Cell Rep 9:701-711

Ding Q, Lee YK, Schaefer EA, Peters DT, Veres A, Kim K, Kuperwasser N, Motola DL, Meissner TB, Hendriks WT et al 
(2013) A TALEN genome-editing system for generating human stem cell-based disease models. Cell Stem Cell 12:238-251

Drost J, van Jaarsveld RH, Ponsioen B, Zimberlin C, van Boxtel R, Buijs A, Sachs N, Overmeer RM, Offerhaus GJ, Begthel $H$ et al (2015) Sequential cancer mutations in cultured human intestinal stem cells. Nature 521:43-47

Dye BR, Hill DR, Ferguson MA, Tsai YH, Nagy MS, Dyal R, Wells JM, Mayhew CN, Nattiv R, Klein OD et al (2015) In vitro generation of human pluripotent stem cell derived lung organoids. Elife. doi:10.7554/eLife.05098

Eiraku M, Watanabe K, Matsuo-Takasaki M, Kawada M, Yonemura S, Matsumura M, Wataya T, Nishiyama A, Muguruma K, Sasai $Y$ (2008) Self-organized formation of polarized cortical tissues from ESCs and its active manipulation by extrinsic signals. Cell Stem Cell 3:519-532

Eiraku M, Takata N, Ishibashi H, Kawada M, Sakakura E, Okuda S, Sekiguchi K, Adachi T, Sasai Y (2011) Self-organizing optic-cup morphogenesis in three-dimensional culture. Nature 472:51-56

Forbester JL, Goulding D, Vallier L, Hannan N, Hale C, Pickard D, Mukhopadhyay S, Dougan G (2015) Interaction of Salmonella enterica Serovar Typhimurium with intestinal organoids derived from human induced pluripotent stem cells. Infect Immun 83:2926-2934

Gao D, Vela I, Sboner A, laquinta PJ, Karthaus WR, Gopalan A, Dowling C, Wanjala JN, Undvall EA, Arora VK et al (2014) Organoid cultures derived from patients with advanced prostate cancer. Cell 159:176-187

Gaspard N, Bouschet T, Hourez R, Dimidschstein J, Naeije G, van den Ameele J, Espuny-Camacho I, Herpoel A, Passante L, Schiffmann SN et al (2008) An intrinsic mechanism of corticogenesis from embryonic stem cells. Nature 455:351-357

Gilbert LA, Larson MH, Morsut L, Liu Z, Brar GA, Torres SE, SternGinossar N, Brandman O, Whitehead EH, Doudna JA et al (2013) CRISPR-mediated modular RNA-guided regulation of transcription in eukaryotes. Cell 154:442-451

Gilbert LA, Horlbeck MA, Adamson B, Villalta JE, Chen Y, Whitehead EH, Guimaraes C, Panning B, Ploegh HL, Bassik MC et al (2014) Genome-scale CRISPR-mediated control of gene repression and activation. Cell 159:647-661

Hilton IB, D'Ippolito AM, Vockley CM, Thakore PI, Crawford GE, Reddy TE, Gersbach CA (2015) Epigenome editing by a CRISPR-Cas9-based acetyltransferase activates genes from promoters and enhancers. Nat Biotechnol 33:510-517

Hisha H, Tanaka T, Kanno S, Tokuyama Y, Komai Y, Ohe S, Yanai H, Omachi T, Ueno H (2013) Establishment of a novel lingual organoid culture system: generation of organoids having mature keratinized epithelium from adult epithelial stem cells. Sci Rep 3:3224

Hsu PD, Lander ES, Zhang F (2014) Development and applications of CRISPR-Cas9 for genome engineering. Cell 157:1262-1278

Huch M, Bonfanti P, Boj SF, Sato T, Loomans CJ, van de Wetering M, Sojoodi M, Li VS, Schuijers J, Gracanin A et al (2013a) Unlimited in vitro expansion of adult bi-potent pancreas progenitors through the Lgr5/R-spondin axis. EMBO J 32:2708-2721

Huch M, Dorrell C, Boj SF, van Es JH, Li VS, van de Wetering M, Sato T, Hamer K, Sasaki N, Finegold MJ et al (2013b) In vitro expansion of single Lgr5+ liver stem cells induced by Wnt-driven regeneration. Nature 494:247-250
Huch M, Gehart H, van Boxtel R, Hamer K, Blokzijl F, Verstegen MM, Ellis E, van Wenum M, Fuchs SA, de Ligt J et al (2015) Long-term culture of genome-stable bipotent stem cells from adult human liver. Cell 160:299-312

Jain IH, Zazzeron L, Goli R, Alexa K, Schatzman-Bone S, Dhillon H, Goldberger O, Peng J, Shalem O, Sanjana NE et al (2016) Hypoxia as a therapy for mitochondrial disease. Science 352:54-61

Jung $P$, Sato T, Merlos-Suárez A, Barriga FM, Iglesias M, Rossell D, Auer H, Gallardo M, Blasco MA, Sancho E et al (2011) Isolation and in vitro expansion of human colonic stem cells. Nat Med 17:1225-1227

Karthaus WR, laquinta PJ, Drost J, Gracanin A, van Boxtel R, Wongvipat J, Dowling CM, Gao D, Begthel $H$, Sachs $N$ et al (2014) Identification of multipotent luminal progenitor cells in human prostate organoid cultures. Cell 159:163-175

Kearns NA, Pham H, Tabak B, Genga RM, Silverstein NJ, Garber M, Maehr R (2015) Functional annotation of native enhancers with a Cas9-histone demethylase fusion. Nat Methods 12:401-403

Koehler KR, Hashino E (2014) 3D mouse embryonic stem cell culture for generating inner ear organoids. Nat Protoc 9:12291244

Koehler KR, Mikosz AM, Molosh AI, Patel D, Hashino E (2013) Generation of inner ear sensory epithelia from pluripotent stem cells in 3D culture. Nature 500:217-221

Koike-Yusa H, Li Y, Tan EP, Velasco-Herrera Mdel C, Yusa K (2014) Genome-wide recessive genetic screening in mammalian cells with a lentiviral CRISPR-guide RNA library. Nat Biotechnol 32:267-273

Komor AC, Kim YB, Packer MS, Zuris JA, Liu DR (2016) Programmable editing of a target base in genomic DNA without double-stranded DNA cleavage. Nature 533:420-424

Konermann S, Brigham MD, Trevino AE, Joung J, Abudayyeh OO, Barcena C, Hsu PD, Habib N, Gootenberg JS, Nishimasu $\mathrm{H}$ et al (2015) Genome-scale transcriptional activation by an engineered CRISPR-Cas9 complex. Nature 517:583-588

Kubben N, Zhang W, Wang L, Voss TC, Yang J, Qu J, Liu GH, Misteli T (2016) Repression of the antioxidant NRF2 pathway in premature aging. Cell 165:1361-1374

Lancaster MA, Knoblich JA (2014) Generation of cerebral organoids from human pluripotent stem cells. Nat Protoc 9:2329-2340

Lancaster MA, Renner M, Martin CA, Wenzel D, Bicknell LS, Hurles ME, Homfray T, Penninger JM, Jackson AP, Knoblich JA (2013) Cerebral organoids model human brain development and microcephaly. Nature 501:373-379

Lee JH, Bhang DH, Beede A, Huang TL, Stripp BR, Bloch KD, Wagers AJ, Tseng YH, Ryeom S, Kim CF (2014) Lung stem cell differentiation in mice directed by endothelial cells via a BMP4NFATc1-thrombospondin-1 axis. Cell 156:440-455

Leslie JL, Huang S, Opp JS, Nagy MS, Kobayashi M, Young VB, Spence JR (2015) Persistence and toxin production by Clostridium difficile within human intestinal organoids result in disruption of epithelial paracellular barrier function. Infect Immun 83:138-145

Li Y, Zhang W, Chang L, Han Y, Sun L, Gong X, Tang H, Liu Z, Deng $\mathrm{H}, \mathrm{Ye} \mathrm{Y}$ (2016) Vitamin $\mathrm{C}$ alleviates aging defects in a stem cell model for Werner syndrome. Protein Cell 7:478-488

Liu GH, Suzuki K, Qu J, Sancho-Martinez I, Yi F, Li M, Kumar S, Nivet E, Kim J, Soligalla RD et al (2011) Targeted gene correction 
of laminopathy-associated LMNA mutations in patient-specific iPSCs. Cell Stem Cell 8:688-694

Ma H, Tu LC, Naseri A, Huisman M, Zhang S, Grunwald D, Pederson T (2016a) Multiplexed labeling of genomic loci with dCas9 and engineered sgRNAs using CRISPRainbow. Nat Biotechnol 34:528-530

Ma Y, Zhang J, Yin W, Zhang Z, Song Y, Chang X (2016b) Targeted AID-mediated mutagenesis(TAM) enables efficient genomic diversification in mammalian cells. Nat Methods. doi:10.1038/ nmeth.4027

Mariani J, Simonini MV, Palejev D, Tomasini L, Coppola G, Szekely AM, Horvath TL, Vaccarino FM (2012) Modeling human cortical development in vitro using induced pluripotent stem cells. Proc Nati Acad Sci USA 109:12770-12775

Mariani J, Coppola G, Zhang P, Abyzov A, Provini L, Tomasini L, Amenduni M, Szekely A, Palejev D, Wilson M et al (2015) FOXG1-dependent dysregulation of GABA/Glutamate neuron differentiation of autism spectrum disorders. Cell 162:375-390

Maschmeyer I, Lorenz AK, Schimek K, Hasenberg T, Ramme AP, Hübner J, Lindner M, Drewell C, Bauer S, Thomas A et al (2015) A four-organ-chip for interconnected long-term co-culture of human intestine, liver, skin and kidney equivalents. Lab Chip 15:2688-2699

Matano M, Date S, Shimokawa M, Takano A, Fujii M, Ohta Y, Watanabe T, Kanai T, Sato T (2015) Modeling colorectal cancer using CRISPR-Cas9-mediated engineering of human intestinal organoids. Nat Med 21:256-262

McCracken KW, Howell JC, Wells JM, Spence JR (2011) Generating human intestinal tissue from pluripotent stem cells in vitro. Nat Protoc 6:1920-1928

McCracken KW, Catá EM, Crawford CM, Sinagoga KL, Schumacher M, Rockich BE, Tsai YH, Mayhew CN, Spence JR, Zavros Y et al (2014) Modeling human development and disease in pluripotent stem-cell-derived gastric organoids. Nature 516:400-404

Mondrinos MJ, Koutzaki S, Jiwanmall E, Li M, Dechadarevian JP, Lelkes PI, Finck CM (2006) Engineering three-dimensional pulmonary tissue constructs. Tissue Eng 12:717-728

Mondrinos MJ, Jones PL, Finck CM, Lelkes PI (2014) Engineering de novo assembly of fetal pulmonary organoids. Tissue Eng Part A 20:2892-2907

Muguruma K, Nishiyama A, Ono Y, Miyawaki H, Mizuhara E, Hori S, Kakizuka A, Obata K, Yanagawa Y, Hirano T et al (2010) Ontogeny-recapitulating generation and tissue integration of ES cell-derived Purkinje cells. Nat Neurosci 13:1171-1180

Muguruma K, Nishiyama A, Kawakami H, Hashimoto K, Sasai Y (2015) Self-organization of polarized cerebellar tissue in 3D culture of human pluripotent stem cells. Cell Rep 10:537-550

Musunuru K (2013) Genome editing of human pluripotent stem cells to generate human cellular disease models. Dis Model Mech 6:896-904

Nanduri LS, Baanstra M, Faber H, Rocchi C, Zwart E, de Haan G, van Os R, Coppes RP (2014) Purification and ex vivo expansion of fully functional salivary gland stem cells. Stem Cell Reports 3:957-964

Nelles DA, Fang MY, O'Connell MR, Xu JL, Markmiller SJ, Doudna JA, Yeo GW (2016) Programmable RNA tracking in live cells with CRISPR/Cas9. Cell 165:488-496
Nishida K, Arazoe T, Yachie N, Banno S, Kakimoto M, Tabata M, Mochizuki M, Miyabe A, Araki M, Hara KY et al (2016) Targeted nucleotide editing using hybrid prokaryotic and vertebrate adaptive immune systems. Science. doi:10.1126/science.aaf8729

Noguchi TK, Ninomiya N, Sekine M, Komazaki S, Wang PC, Asashima M, Kurisaki A (2015) Generation of stomch tissue from mosue embryonic stem cell. Nat Cell Biol 17:984-993

Ogawa M, Ogawa S, Bear CE, Ahmadi S, Chin S, Li B, Grompe M, Keller G, Kamath BM, Ghanekar A (2015) Directed differentiation of cholangiocytes from human pluripotent stem cells. Nat Biotechnol 33:853-861

Ootani A, Li X, Sangiorgi E, Ho QT, Ueno H, Toda S, Sugihara $H$, Fujimoto K, Weissman IL, Capecchi MR et al (2009) Sustained in vitro intestinal epithelial culture within a Wnt-dependent stem cell niche. Nat Med 15:701-706

Ozone C, Suga H, Eiraku M, Kadoshima T, Yonemura S, Takata N, Oiso Y, Tsuji T, Sasai Y (2016) Functional anterior pituitary generated in self-organizing culture of human embryonic stem cells. Nat Commun 7:10351

Parnas O, Jovanovic M, Eisenhaure TM, Herbst RH, Dixit A, Ye CJ, Przybylski D, Platt RJ, Tirosh I, Sanjana NE et al (2015) A Genome-wide CRISPR screen in primary immune cells to dissect regulatory networks. Cell 162:675-686

Perez-Pinera P, Kocak DD, Vockley CM, Adler AF, Kabadi AM, Polstein LR, Thakore PI, Glass KA, Ousterout DG, Leong KW et al (2013a) RNA-guided gene activation by CRISPR-Cas9based transcription factors. Nat Methods 10:973-976

Perez-Pinera P, Ousterout DG, Brunger JM, Farin AM, Glass KA, Guilak F, Crawford GE, Hartemink AJ, Gersbach CA (2013b) Synergistic and tunable human gene activation by combinations of synthetic transcription factors. Nat Methods 10:239-242

Qi LS, Larson MH, Gilbert LA, Doudna JA, Weissman JS, Arkin AP, Lim WA (2013) Repurposing CRISPR as an RNA-guided platform for sequence-specific control of gene expression. Cell 152:1173-1183

Qian X, Nguyen HN, Song MM, Hadiono C, Ogden SC, Hammack C, Yao B, Hamersky GR, Jacob F, Zhong C et al (2016) Brainregion-specific organoids using mini-bioreactors for modeling ZIKV exposure. Cell 165:1238-1254

Ren W, Lewandowski BC, Watson J, Aihara E, Iwatsuki K, Bachmanov AA, Margolskee RF, Jiang P (2014) Single Lgr5- or Lgr6- expressing taste stem/progenitor cells generate taste bud cells ex vivo. Proc Natl Acad Sci USA 111:16401-16406

Sampaziotis F, Cardoso de Brito M, Madrigal P, Bertero A, SaebParsy K, Soares FA, Schrumpf E, Melum E, Karlsen TH, Bradley JA et al (2015) Cholangiocytes derived from human induced pluripotent stem cells for disease modeling and drug validation. Nat Biotechnol 33:845-852

Sanjana NE, Wright J, Zheng K, Shalem O, Fontanillas P, Joung J, Cheng C, Regev A, Zhang F (2016) High-resolution interrogation of functional elements in the noncoding genome. Science 353:1545-1549

Sato T, Vries RG, Snippert HJ, van de Wetering M, Barker N, Stange DE, van Es JH, Abo A, Kujala P, Peters PJ et al (2009) Single Lgr5 stem cells build crypt-villus structures in vitro without a mesenchymal niche. Nature 459:262-265

Sato T, Stange DE, Ferrante M, Vries RG, Van Es JH, Van den Brink S, Van Houdt WJ, Pronk A, Van Gorp J et al (2011) Long-term 
expansion of epithelial organoids from human colon, adenoma, adenocarcinoma, and Barrett's epithelium. Gastroenterology 141:1762-1772

Schlaermann P, Toelle B, Berger H, Schmidt SC, Glanemann M, Ordemann J, Bartfeld S, Mollenkopf HJ, Meyer TF (2016) A novel human gastric primary cell culture system for modeling Helicobacter pylori infection in vitro. Gut 65:201-213

Schmidt JC, Zaug AJ, Cech TR (2016) Live cell imaging reveals the dynamics of telomerase recruitment to telomeres. Cell 166:11881197

Schweiger PJ, Jensen KB (2016) Modeling human disease using organotypic cultures. Curr Opin Cell Biol 43:22-29

Shalem O, Sanjana NE, Hartenian E, Shi X, Scott DA, Mikkelsen TS, Heckl D, Ebert BL, Root DE, Doench JG et al (2014) Genomescale CRISPR-Cas9 knockout screening in human cells. Science 343:84-87

Shi J, Zhao Y, Wang K, Shi X, Wang Y, Huang H, Zhuang Y, Cai T, Wang $F$, Shao $F$ (2015) Cleavage of GSDMD by inflammatory caspases determines pyroptotic cell death. Nature 526:660-665

Spence JR, Mayhew CN, Rankin SA, Kuhar MF, Vallance JE, Tolle K, Hoskins EE, Kalinichenko VV, Wells SI, Zorn AM et al (2011) Directed differentiation of human pluripotent stem cells into intestinal tissue in vitro. Nature 470:105-109

Stange DE, Koo BK, Huch M, Sibbel G, Basak O, Lyubimova A, Kujala P, Bartfeld S, Koster J, Geahlen JH et al (2013) Differentiated Troy+ chife cells act as reserve stem cells to generate all lineages of the stomach epithelium. Cell 155:357368

Suga $\mathrm{H}$, Kadoshima T, Minaguchi M, Ohgushi M, Soen M, Nakano T, Takata N, Wataya T, Muguruma K, Miyoshi H et al (2011) Selfformation of functional adenohypophysis in three-dimensional culture. Nature 480:57-62

Takahashi K, Tanabe K, Ohnuki M, Narita M, Ichisaka T, Tomoda K, Yamanaka S (2007) Induction of pluripotent stem cells from adult human fibroblasts by defined factors. Cell 131:861-872

Takasato M, Er PX, Chiu HS, Maier B, Baillie GJ, Ferguson C, Parton RG, Wolvetang EJ, Roost MS, de Sousa Chuva, Lopes SM (2015) Kidney organoids from human iPS cells contain multiple lineages and model human nephrogenesis. Nature 526:564-568

Takebe T, Sekine K, Enomura M, Koike H, Kimura M, Ogaeri T, Zhang RR, Ueno Y, Zheng YW, Koike N et al (2013) Vascularized and functional human liver from an iPSC-derived organ bud transplant. Nature 499:481-484

Takebe T, Zhang RR, Koike H, Kimura M, Yoshizawa E, Enomura M, Koike N, Sekine K, Taniguchi H (2014) Generation of a vascularized and functional human liver from an iPSC-derived organ bud transplant. Nat Protoc 9:396-409

Thakore PI, D'Ippolito AM, Song L, Safi A, Shivakumar NK, Kabadi AM, Reddy TE, Crawford GE, Gersbach CA (2015) Highly specific epigenome editing by CRISPR-Cas9 repressors for silencing of distal regulatory elements. Nat Methods 12:1143-1149

van de Wetering $M$, Francies HE, Francis JM, Bounova G, lorio F, Pronk A, van Houdt W, van Gorp J, Taylor-Weiner A, Kester L et al (2015) Prospective derivation of a living organoid biobank of colorectal cancer patients. Cell 161:933-945
Visconti RP, Kasyanov V, Gentile C, Zhang J, Markwald RR, Mironov $V$ (2010) Towards organ printing: engineering an intra-organ branched vascular tree. Expert Opin Biol Ther 10:409-420

Wang F, Qi LS (2016) Applications of CRISPR genome engineering in cell biology. Trends Cell Biol 26:875-888

Wang T, Wei JJ, Sabatini DM, Lander ES (2014) Genetic screens in human cells using the CRISPR-Cas9 system. Science 343:8084

Wang X, Yamamoto Y, Wilson LH, Zhang T, Howitt BE, Farrow MA, Kern F, Ning G, Hong Y, Khor CC et al (2015) Cloning and variation of ground state intestinal stem cells. Nature 522:173178

Watson CL, Mahe MM, Múnera J, Howell JC, Sundaram N, Poling HM, Schweitzer JI, Vallance JE, Mayhew CN, Sun Y et al (2014) An in vivo model of human small intestine using pluripotent stem cells. Nat Med 20:1310-1314

Wilson SS, Tocchi A, Holly MK, Parks WC, Smith JG (2015) A small intestinal organoid model of non-invasive enteric pathogenepithelial cell interactions. Mucosal Immunol 8:352-361

Workman MJ, Mahe MM, Trisno S, Poling HM, Watson CL, Sundaram N, Chang CF, Schiesser J, Aubert P, Stanley EG (2016) Engineered human pluripotent-stem-cell-derived intestinal tissues with a functional enteric nervous system. Nat Med. doi: 10.1038/nm.4233

Wroblewski LE, Piazuelo MB, Chaturvedi R, Schumacher M, Aihara E, Feng R, Noto JM, Delgado A, Israel DA, Zavros Y (2015) Helicobacter pylori targets cancer-associated apical-junctional constituents in gastroids and gastric epithelial cells. Gut 64:720730

Yin X, Farin HF, van Es JH, Clevers H, Langer R, Karp JM (2014) Niche-independent high-purify cultures of Lgr5+ intestinal stem cells and their progeny. Nat Methods 11:106-112

Yin X, Mead BE, Safaee H, Langer R, Karp JM, Levy O (2016) Engieering stem cell organoids. Cell Stem Cell 18:25-38

Yu J, Vodyanik MA, Smuga-Otto K, Antosiewicz-Bourget J, Frane JL, Tian S, Nie J, Jonsdottir GA, Ruotti V, Stewart R et al (2007) Induced pluripotent stem cell lines derived from human somatic cells. Science 318:1917-1920

Zhang YG, Wu S, Xia Y, Sun J (2014) Salmonella-infected cryptderived intestinal organoid culture system for host-bacterial interactions. Physiol Rep 2(9):e12147

Zhang W, Li J, Suzuki K, Qu J, Wang P, Zhou J, Liu X, Ren R, Xu X, Ocampo A et al (2015) A Werner syndrome stem cell model unveils heterochromatin alterations as a driver of human aging. Science 348:1160-1163

Zhou Y, Zhu S, Cai C, Yuan P, Li C, Huang Y, Wei W (2014) Highthroughput screening of a CRISPR/Cas9 library for functional genomics in human cells. Nature 509:487-491

Zhu S, Li W, Liu J, Chen CH, Liao Q, Xu P, Xu H, Xiao T, Cao Z, Peng $J$ et al (2016) Genome-scale deletion screening of human long non-coding RNAs using a paired-guided RNA CRISPRCas9 library. Nat Biotechnol. doi: 10.1038/nbt.3715 